Case Report

\title{
Report of Salmonella Meningitis in 3-Month-Old Children
}

\section{Meidry Tinasia Teslatu*, Dewi Sutriani Mahalini, I Gusti Ngurah Made Suwarba}

Sanglah Hospital-Department of Pediatrics, Udayana University, Denpasar-Bali, Indonesia

Email address:

meidrytes@gmail.com (M. T. Teslatu),dewi_sutriani@unud.ac.id (D. S. Mahalini)

${ }^{*}$ Corresponding author

\section{To cite this article:}

Meidry Tinasia Teslatu, Dewi Sutriani Mahalini, I Gusti Ngurah Made Suwarba. Report of Salmonella Meningitis in 3-Month-Old Children. Clinical Neurology and Neuroscience. Vol. 5, No. 3, 2021, pp. 68-71. doi: 10.11648/j.cnn.20210503.17

Received: August 19, 2021; Accepted: September 2, 2021; Published: September 27, 2021

\begin{abstract}
Salmonella meningitis is a rare infection, unusual manifestation of salmonellosis and mostly among infants and young children. Meningitis due to Salmonella carries a higher morbidity and mortality than that caused by other bacteria. Salmonella is more commonly found in contaminated food and is included in gram-negative rods. The diagnosis is made based on the findings of Salmonella bacteria on cerebrospinal fluid (CSF). Salmonella meningitis therapy requires antimicroba that are able to penetrate the blood brain barrier and minimum treatment for at least 4 weeks to prevent death, recurrence and permanent adverse outcomes. Early diagnose of acute complications and a follow-up plans for early assessment of development are very important. Among survivors, common complications are seizure, hydrocephalus, subdural empyemas and permanent disabilities suc as retardation, paresis, athetosis and visual disturbances. We present a 3 months-old male with main complain seizure, fever, and bulging of fontanelle. Neurological examination found no abnormalities, no meningeal sign, physiologic reflex was normal and no sign of lateralization. Complete blood count found with normal leukocytes and mild anemia hypochromic microcytic. Cerebrospinal fluid (CSF) analysis showed positive Pandy and None tests, high cell count, low glucose level, high protein level. The results of CSF culture and blood culture found Salmonella sp. Head CT scan reveals subchronic subdural hygroma with brachycephaly. Patient treated with third generation of cephalosporins (ceftriaxone) for 4 weeks. Prompt use of targeted antibiotics with adequate dosage and duration plays a significant role on prognosis. Patient discharge form hospital with no sign of sequele and good prognosis.
\end{abstract}

Keywords: Salmonella Meningitis, Gram Negative Bacterial, Brachycephaly, Hygroma Subdural, Infants

\section{Introduction}

Bacterial meningitis is an important pediatric disease because it generally has a poor prognosis in infants and young children. Good prognosis and no neurological sequelae can be expected if the disease is diagnosed early and treated promptly. $[1,2]$ Meningitis due to Salmonella is a pathogenic infection of children in many developing countries, accounting for $5-13 \%$ of acute bacterial meningitis that occurred in the 1980-2000s. [3] It is, however, relatively common in developing countries such as Africa. In Africa, Salmonella is the fourth leading cause of bacterial meningitis in children with a percentage of $13 \%$ after Streptococcus pneumoniae, Haemophilus influenza, and Neisseria meningitidis. [3-5] Until recent in Indonesia there is no data that describes the incidence of Salmonella meningitis in children. Salmonella meningitis should be considered if Gram-negative rods are present in the cerebrospinal fluid (CSF) examination. [6]

The treatment of Salmonella meningitis requires antimicroba that are capable of penetrating CSF and combination therapy of third generation cephalosporins (such as ceftriaxone, cefotaxime and ceftazidime) were the best choice for Salmonella meningitis. Meningitis by Salmonella is a rare case ( $1 \%$ or less) that found in children, with higher rates of complications, recurrence and mortality (50-70\%). [4] Minimum treatment between 4-6 weeks can reduce the incidence of relapse, mortality rate, and significant neurologic sequelae including cerebral palsy, visual and hearing impairment and mental retardation. [4-6, 8] This case reports Salmonella meningitis in 3-month-old male presenting with seizure and fever. 


\section{Case Report}

A 3-month-old male was referred from the district hospital to the Sanglah Hospital, with main complained of seizures. Seizure happened 1 time for approximately 1 minute, and the patient has a seizure while in the district hospital. Seizures appeared with tonic clonic seizure and eyes glaring upwards with oxygen desaturation less then 90\%. Previously the patient was conscious and active as before, seizures accompanied by fever with temperature measured $40^{\circ} \mathrm{C}$. Fever was complained since 1 day before admitted to hospital. The parents also complained of a bulging of fontanelle, which had been realized since the morning before entering the hospital. Other complaints such as coughing, runny nose, vomiting, watery ears, pain in the ear and redness of the ear were denied. There was no history of traumatic event on head. The patient still consume the same amount of breast milk and formula milk before illnes. Defecation and urination were normal. Last urination was approximately 2 hours prior hospitalization.

A history of contact with a comfirmed case of COVID-19 were denied. The mother complained fever 1-2 days before the patient had a fever and only consume antipyretic drugs. There was no family member who had the same history or similar symptoms with patient. Patient was the only child in his family. Patient was born full term in caesarean section because of mother's narrow hips. The birth weight of the patient was 2700 grams, body length of $50 \mathrm{~cm}$, head circumference was forgotten and vigorous baby. No history of birth trauma. The patient's growth and development were appropriate for age. Patient already received basic immunization in accordance with Indonesian Health Ministry's Immunization program.

The general examination showed GCS E4V5M6, normal vital sign, oxygen saturation $99 \%$ in room air. Body weight and height of the patient's are $5.5 \mathrm{~kg}$ (Z-score $0-2 \mathrm{SD}$, WHO chart; normal), $62 \mathrm{~cm}$ (Z-score 0-2 SD, WHO chart; normal). Pupil reflex were positive and isokor. Physical examination showed normocephali, bulging fontanel, and head circumference was $40 \mathrm{~cm}$. No anemia and icteric eyes. Physical examination of the chest, heart and abdomen were normal. No liver or spleen enlargement, no tenderness or distension in the abdomen. There was no meningeal sign found. The physiologic reflex was normal and there was no sign of lateralization.

The complete blood count result showed leukocytes $6.4 \mathrm{x}$ $10 \% / \mu \mathrm{L}$; neutrophils $51.4 \%$; lymphocytes $44.3 \%$, eosinophil $0.5 \%$, haemoglobin $9.8 \mathrm{~g} / \mathrm{dL}$; MCV $75.9 \mathrm{fL}$; MCH $26.1 \mathrm{pg}$; MCHC $34.3 \mathrm{~g} / \mathrm{dL}$; RDW $12.8 \%$; hematocrite $28.6 \%$; platelets $410 \times 10^{3} / \mu \mathrm{L}$, normal blood sugar $(103 \mathrm{mg} / \mathrm{dL})$, mild hyponatremia (sodium $130 \mathrm{mmol} / \mathrm{L}$, potassium $4.78 \mathrm{mmol} / \mathrm{L}$, calsium $9.2 \mathrm{mg} / \mathrm{dL}$, chloride $99.3 \mathrm{mmol} / \mathrm{L}$ ), kidney function is normal (ureum $7.70 \mathrm{mg} / \mathrm{dL}$, creatinine $0.22 \mathrm{mg} / \mathrm{dL}$ ), and SARS CoV-2 antibody test was non-reactive. Cerebrospinal fluid (CSF) analysis showed Pandy test $(+2)$ and None test $(+2)$, colorless, leucocyte cell count 343 (mononuclear 45\%, polymorphonuclear 55\%), low glucose level (4 mg/dL), high protein level $(121.30 \mathrm{mg} / \mathrm{dL})$, no blood, no erythrocytes. Complete feces showed greenish yellow color, positive mucus, no blood, microscopic (0-1 leukocytes, negative erythrocytes), negative amoeba, negative cyst, negative helminth. CT Scan examination revealed no bleeding, infarction, intracerebral or intracerebellar space occupation lession (SOL) were seen, subchronic subdural hygroma in the bilateral frontoparietal region, ultrabrachycephaly with fontanella diastasis measured $+/-5.6 \mathrm{~cm}$. Chest X-ray with infiltrates in the middle zone and lower right lung but there are no symptoms or physical examination that suggest a pulmonary infection. Blood culture reveal with Salmonella $s p p$. and from CSF culture was found with Salmonella spp. as well.

Patient was diagnosed with Salmonella Meningitis, confirmed bacteremia, subdural hygroma and brachycephaly. Patient treated with ceftriaxone, a third-generation of cephalosporins for 4 weeks. During routine follow up, the patient's responded well to the treatment and his condition improved. Patient discharged form hospital with no sign of sequelae and had a good prognosis.

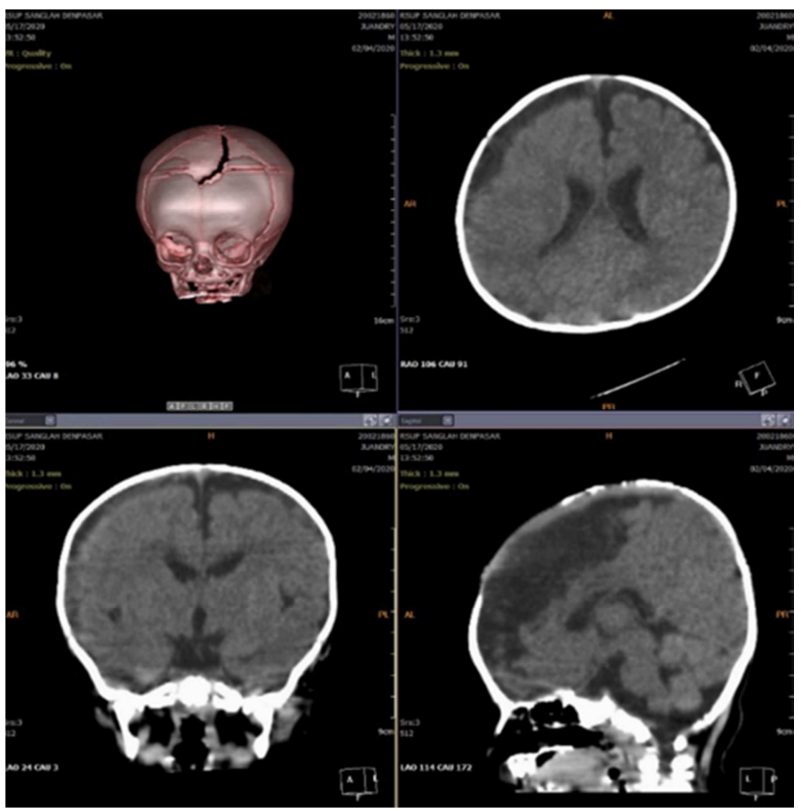

Figure 1. Head CT Scan without contras. Ultrabrachycephaly with a measured fontanella diastasis $+/-5.6 \mathrm{~cm}$. and subchronic subdural hygroma in the bilateral frontoparietal region.

\section{Discussion}

The worldwide incidence of Salmonella infections has been found to have increased significantly over the last few years in many countries. Salmonella bacteremia and vascular infection are reported in $8 \%$ of cases and the remainder such as meningitis, septic arthritis, and osteomyelitis are also found to be complications of Salmonella bacteremia but their occurrence is very rare. $[10,18]$

Salmonella meningitis can occur in the first four months of life with a percentage of $50-75 \%$, this is the reason that distinguishes salmonella meningitis from other bacterial meningitis. [9] Weatherhead et al. study in 112 patients with Salmonella meningitis reports all patients were under the age of 4 months, with ages ranging from 7 days to 4 months (mean 
age: 7.5 weeks). [5] Most of the patients were male and previously healthy infants. [3, 5] A recent study in the pediatric age group revealed that $24 \%$ of children with Salmonella infection had risk factors such as HIV infection, oncological disease, malnutrition, pneumonia or low birth weight. In Africa, children with salmonella infection are mostly found at the age of 6-36 months. [19] In our case, Salmonella meningitis occurs in 3-month-old male, previously healthy, full term infants.

Port de entre salmonella meningitis infection can be through contaminated food, transplacental, breast milk and direct contact with reptile carriers. [11] The source of infection and mode of transmission in our patient is not clear. The most common spread of Salmonella infection is through the faecal-oral route, and non-typhoidal salmonella are a common cause of foodborne illnesses. [12]

Pathogenesis of Salmonella meningitis is similar with bacterial meningitis which suggests that bacteria entering CSF will stimulate endothelial cells and CNS macrophage cells to produce inflammatory mediators, such as interleukin-1 (IL-1) and tumor necrosis factor (TNF). Inflammatory mediators induce hyperemia of the cerebral blood vessels accompanied by migration of neutrophils into the subarachnoid space, further stimulating congestion and increasing the permeability of blood vessels, facilitating the adhesion of phagocyte cells and polymorphonuclear cells to penetrate blood vessels through the tight junction and phagocyte the bacteria. [2, 13] Polymorphonuclear (PMN) cells that phagocyte bacteria are gradually replaced by lymphocyte cells, monocytes and histiocytes that increase in number lead to pleocytosis or increased cell and protein CSF, producing fibrinogen exudate. Second-week infections appear fibroblast cells that play a role in the organization of exudates, resulting in fibrosis tissue in the lining of the brain causing attachment that occurs in the basal cysterna causing increased intracranial pressure, which in turn results in decreased cerebral blood flow and hydrocephalus complications. 2,16 Increased in intracranial pressure and inflammation lead to oxygen deprivation. Hypoxia increases lactate metabolism of CSF, CSF glucose decreases so that sufferers decrease consciousness, seizures to coma. [2]

Clinical manifestations of Salmonella meningitis include fever, vomiting, diarrhea, irritable, recurrent seizures, tonic-clonic seizures, sometimes high pitch cry in infants. [3, 5] The apparent classic sign is bulging of anterior fontanel, while the Brudzinski and Kernig signs are difficult to evaluate. In older children, local symptoms of central nervous system (CNS) include headache, somnolence, and meningal signs, ie neck stiffness, Kernig sign, and Brudzinski sign. However, infants aged 3 months to 2 years rarely give a classic overview of bacterial meningitis. The duration of symptoms prior to admission varied from 1 to 10 days (mean 3.0 days). [5] In this case the patient had fever, bulging fontanel, and seizure. The patient is conscious, no meningeal sign found.

Diagnosis of meningitis is established with clinical signs and symptoms as well as laboratory investigations. The definitive diagnosis of meningitis through CSF examination with the discovery of bacteria or viruses. If Salmonella spp. are grown from a site outside the central nervous system (CNS) in any unwell child, especially one under 6 months of age, consideration should be given to performance of a lumbar puncture. $[6,13]$ The CSF analysis for bacterial meningitis often show an increased cell count up to thousands with PMN cell dominance, there may be an increase in white blood cells, but often within normal limits, even low in the neonate, increased protein, and decreased glucose levels. [14] In this case, our patient have normal leukocytes count in routine blood test, liquor analysis showed clear color, increased none and pandy test, high leucocyte cell count, low glucose level, high protein level, CSF culture and blood culture results found Salmonella $s p$. Judging from clinical manifestation such as fever, seizure and bulging fontanel, this patient was diagnosed with bacterial meningitis.

There are no specific guidelines for the treatment of salmonella meningitis. The current therapy for salmonella meningitis is based on case reports or series and expert opinion. [6] Management of bacterial meningitis include administration of empiric antibiotic, supportive treatment, and management of the complication. [14] Antibiotics used in salmonella meningitis must be able to cross the blood brain barrier and salmonella is an intracellular facultative bacteria that can cause antibiotic resistance. [11] Third-generation cephalosporins are often used for the initial treatment of meningitis caused by Gram-negative enteric bacilli, minimum duration of treatment 4-6 weeks to prevent relapses [6, 11].

Ceftriaxone has poor intracellular penetration; but better than both gentamicin and chloramphenicol; and enter the intercellular compartment that contains engulfed bacteria only by diffusion. In such a case the intracellular ability of the antibiotics is dependent on the extracellular concentration achieved. Therefore, American Academy of Pediatrics recommends that for successful treatment of meningitis caused by Salmonella species high dose of the third generation cephalosporin's should be used and the therapy should be continued for 4 weeks to ensure complete killing of the organism and to prevent relapse. [6, 13, 15-17] Supportive treatment for patients with bacterial meningitis include seizure management, antiinflammation, and nutritional management. Seizure management is determined by patients condition and acute seizure management guideline. Acute management include $5 \mathrm{mg}$ diazepam suppositoria for less than $12 \mathrm{~kg}$ body weight and $10 \mathrm{mg}$ for patients with more than $12 \mathrm{~kg}$ body weight, maximum 2 times with a distance of 5 minutes. If intravenous access has been installed, $0.2-0.5 \mathrm{mg} / \mathrm{kg}$ diazepam can be administered. If the seizure continue, phenobarbital and or phenytoin loading dose $20 \mathrm{mg} / \mathrm{kg} /$ day (max dose $1000 \mathrm{mg}$ ) can be given intravenously. [7] Maintenance dose 5 $\mathrm{mg} / \mathrm{kg} / \mathrm{day}$ should be given after that. In ASIA, there were several reports of cases of salmonella meningitis in children aged 1 day to 14 months who were treated with third generation cephalosporin antibiotics with a minimum duration of 4 weeks of treatment getting a good prognosis without neurological complications $[18,20,21]$ In this case, the patient administered ceftriaxon antibiotics as definitive 
therapy according to CSF culture with dose $100 \mathrm{mg} / \mathrm{kg} / \mathrm{day}$, planned for 4 weeks.

The morbidity of salmonella meningitis is associated with very high range from $50-90 \%$, with various complications, especially in neonates. Acute hydrocephalus, convulsions, ventriculitis, abscess, subdural empyema, and long-term neurologic abnormalities are known to occur in many cases. [3] In the past, mortality rates due to meningitis were 40 to $70 \%$, these numbers have reduced significantly due to optimal diagnosis and management. Early diagnosis of the Salmonella meningitis together with an appropriate choice of the antibiotic at the initial presentation, followed by their prolonged therapy, and regular follow up till patients completely recover can improve the outcome significantly. [12] Our patient responded well with treatment, no sequelae was found during the follow up, thus long term follow up is important to ensure the outcome of this patient.

\section{Conclusion}

Salmonella meningitis is a very rare infection that require special attention, and still a threat to children under the age of two. Three months old male reported with salmonella meningitis at Sanglah General Hospital Bali, Indonesia. In our case the infant developed meningitis as complication of systemic infection probably due to his early age. Considering our literature review, we believe that the patient should have been kept on antibiotics for at least four weeks to prevent relaps and better outcome. Early diagnosis and adequate antibiotics can lead to a better prognosis. The longterm monitoring for survivors is useful to improve the functional prognosis.

\section{References}

[1] Saharso D, Pusponegoro HD, Mangunatmadja I, Handyastuti S, Widodo DP, Erny. Meningitis bakterialis. In: Pudjiadi AH, Hegar B, Handryastuti S, Idris NS, Gandaputra EP, Harmoniati ED, editors. Pedoman pelayanan medis Ikatan Dokter Anak Indonesia. 1st ed. Jakarta: Badan penerbit IDAI; 2010. p. 189-92.

[2] Saharso D, Hidayati SN. Meningitis bakterialis. In: Soetomenggolo TS, Ismael S, editors. Buku Ajar Neurologi Anak. $1^{\text {st }}$ ed. Jakarta: Badan Penerbit IDAI; 1999. p. 339-52.

[3] Wu HM, Huang WY, Lee ML, et al. Clinical features, acute complications, and outcome of Salmonella meningitis in children under one year of age in Taiwan. BMC Infectious Disease. 2011; 11 (30); 1-7.

[4] Owusu-Ofuri A and Scheld WM. Treatment of Salmonella meningitis: two case reports and a review of the literature. International Journal Infectious Diseases. 2003; 7: 53-60.

[5] Weatherhead JE, Revell P, and Munoz FM. Salmonella meningitis in children at Texas Children's Hospital. Journal of Pediatric Infectious Disease. 2012; 7 (2012): 9-14.

[6] Price EH, Workman MR, and de Louvois J. Antibiotics for Salmonella meningitis in children. Journal of Antimicrobial Chemotherapy. 2000; 46: 653-655.
[7] Cohn AC, Schmidt M, Arnold KE, MacNeil JR, Baumbach J, Craig AS, Theodore J, et al. Changes in Neisseria meningitidis disease epidemiology in the United States, 1998 \pm 2007 : implications for prevention of meningococcal disease. Clinical infectious diseases: an official publication of the Infectious Diseases Society of America. 2010; 50 (2): 184 \pm 91.

[8] Tunkel AR, Hartman BJ, Kaplan SL, Kaufman BA, Ross KL, Scheld WM, et al. Practice guielines for the management of bacterial meningitis. Clin Infect Dis. 2004; 39: 1269-84.

[9] Nwadike VU, Fowotade A, Tuta KE, Olusanya OO. A rare case of salmonella typhi meningitis in an eleven month old infant: a case report. Annals of Ibadan Postgraduate Medicine. 2012; 10 (1): 38-39.

[10] Alkindi N, Khan JM, Almasri N. Salmonella Meningitis. American Journal Clinical Microbiology Antimicrobials. 2021; 4 (1): 1049.

[11] Ana De Malet, Sheila Ingerto, Israel Gañán, "Meningitis Caused by Salmonella Newport in a Five-Year-Old Child", Case Reports in Infectious Diseases. 2016. Article ID 2145805.

[12] Elsawy AM et al. Salmonella typhi Meningitis in an Infant: A Case Report. Egyptian Journal of Medical Microbiology. 2018; 27 (3): 93-96.

[13] Swanson D. Meningitis. Pediatrics in review. 2015; 36: 514-26.

[14] Rowland TL, McHugh SM, Deighton J, Dearman RJ, Ewan PW, Kimber I. Differential regulation by thalidomide and dexamethasone of cytokine expression in human peripheral blood mononuclear cells. Immunopharmacology. $1998 \mathrm{Jul} ; 40$ (1): 11-20.

[15] Adhikary R, Joshi S, Ramakrishnan M. Salmonella typhimurium meningitis in infancy. Indian J Crit Care Med. 2013; 17 (6): 392-393. doi: 10.4103/0972-5229.123464.

[16] Rowe SY, Daily PJ, Slutsker L, Kassenborg HD, Hardnett FP, Daily PJ, et al. Breast-feeding decreases the risk of sporadic salmonellosis among infants in FoodNet sites. Clinical Infectious Disease. 2004; 38 (Suppl 3): S262-70.

[17] Fomda BA, Naik MI, Charoo BA, Reyaz N, Bhat JA, Maroof P. Recurrent meningitis due to Salmonella enteritidis: A case report from Kashmir India. Indian Journal Medical Microbiology. 2012; 30 (4): 474-6.

[18] Zhao J, Hua C, Zhou M, Wang H, Xie Y, Wang G. A case report of Salmonella meningitis in three Chinese children and a literature review. Res Square. 2020; 1 (1): 63494.

[19] Barrios P, Badía F, Misa V, Mota MI, Martinez A, Mariño H, Algorta G, Prego J, Pírez MC. A five-year experience with zoonotic Salmonella at a pediatric reference centre. Revista Chilena de Infectologia: Organo Oficial de la Sociedad Chilena de Infectologia. 2017; 34 (4): 359-64.

[20] Alkindi N, Almasri N, Khan J. Salmonella Meningitis. American Journal of Clinical Microbiology and Antimicrobials. 2021; 4 (1): 1049.

[21] Kiymet E, Bayram N, Devrim L, et al. A 30-day old Infant with Meningitis Due To Salmonella Enteriditis: A Case Report. J Pediatrs Inf. 2020; 14 (2); e76-e78. 